\title{
Modelling the Financial Framework of the Pharmacotherapy Cost of Rare Diseases with Orphan Medicines-Part II
}

\author{
Albena Zlatareva1, Konstantin Tachkov', Milena Stoicheva², Svetla Georgieva ${ }^{3}$, \\ Maria Krasteva Bozhkova ${ }^{4}$, Guenka Petrova ${ }^{1}$ \\ ${ }^{1}$ Faculty of Pharmacy, Medical University of Sofia, Sofia, Bulgaria \\ ${ }^{2}$ Faculty of Public Health, Medical University of Sofia, Sofia, Bulgaria \\ "Alexandrovska" Hospital, Medical University of Sofia, Sofia, Bulgaria \\ ${ }^{4}$ Medicine College, Medical University of Plovdiv, Plovdiv, Bulgaria \\ Email: gpetrova@pharmfac.net
}

Received 18 March 2014; revised 15 April 2014; accepted 25 April 2014

Copyright (C) 2014 by authors and Scientific Research Publishing Inc.

This work is licensed under the Creative Commons Attribution International License (CC BY). http://creativecommons.org/licenses/by/4.0/

cC) (7) Open Access

\begin{abstract}
The objective of this analysis is to build a regression cost model towards the data for budget expenditures for rare diseases in Bulgaria and to evaluate the future impact on the health care budget. Four regression cost models were built based on previously published results of the macro costing top down financial analysis of the expenditures for medicines spent by the 3rd party payer. In Bulgaria that is the national health insurance fund (NHIF). The previous analysis covers the period 2010-2013 year and the regression models are forecasting the future expenditures till 2016 year. Four models follow linear regression among the researched variables and expected future changes. The cost of all reimbursed medicines, dietary food and medical devices is expected to reach 703 million of BGN, medicines expenditures are expected to reach 680 million, number of reimbursed medicines is expected to be 2315, and expenditures for rare diseases will reach 96 million of BGN. The number of patients, as well as the budget allocated for orphan drugs is increasing in time, with the addition of the critical fact that the oncology drugs were transferred to the NHIF. This is a positive result based on a number of factors, but also reveals the importance of carefully predicting and allocating the funds needed for orphan drugs. The model analyzing costs for pharmacotherapy shows that these expenses will increase linearly in the next three years, which in turn will put the financial capabilities of the NHIF to the test, as well as limit the access of patients to orphan drugs.
\end{abstract}

\section{Keywords}

Health Care Expenditures, Cost of Pharmacotherapy, Rare Diseases Financing 


\section{Introduction}

The pharmacotherapy of rare diseases engages a lot of financial resources of the affected families or of the community [1]-[4]. In the last 10 years, because of the EU's programmes targeted at studies and therapy of rare diseases, many resources were relocated towards treatment, which in turn increased the effectiveness of therapy [5]-[7]. Alongside this fact, because of the rare nature of such diseases and the need of highly qualified help, many member countries began setting funds aside towards their therapy [8] [9]. A series of authors have researched the topic of increased expenses for rare diseases as a burden to community healthcare savings funds [10] [11]. Others believe that this rapid increase in spending will be short-term and as such do not threaten the aforementioned funds [5].

Central and Eastern European countries have conducted studies, which recover that the pharmacotherapy need of patients suffering from rare diseases has not been satisfied and they do not have access to their respective treatment [12].

Moreover the analyses of budget and regional differences show that the therapy of rare diseases consumes a lot of financial resources and requires detailed observations and analyses of the medical, humanistic and social reasons for the differences [13] [14]. In this respect creation of the financial model to forecast the future costs development is necessary for appropriate budget planning and allocation.

The objective of this analysis is to forecast the data for budget expenditures for rare diseases in Bulgaria and to evaluate the future impact on the health care budget.

\section{Method}

A regression cost model was build based on previously published results of the macro costing top down financial analysis of the expenditures for medicines spent by the 3rd party payer in Bulgaria that is the national health insurance fund (NHIF) [3]. The analysis covers the period 2010-2013 year and the regression model is forecasting the future expenditures till 2016 year.

The following relations were forecasted:

- the expenditures for ambulatory medicines therapy, medical devices and dietary food;

- the expenditures for the sum reimbursed by the third party payer only for medicines;

- the changes in the number of reimbursed medicines;

- the cost the therapy of rare diseases.

All costs are presented in local currency at the exchange rate of $1 €=1.95$ BGN.

\section{Results}

The first model developed analyzes the change in reimbursed sum for medical devices, dietary foods for special medical needs and medicinal products (Figure 1). It forecasts the total sum, which the NHIF pays for ambulatory patients.

The mathematical model is describes a linear regression, built on existing budget data regarding the reimbursed sums by the NHIF, with a base year of $1=2010$, and subsequent years $2=2011,3=2012,4=2013$. The following regression equation describes the model:

Reimbursed sum $=353,300,000+50,060,000 \times$ year.

Correlation coefficient $\mathrm{R}=0.952$.

Coefficient of determination $\mathrm{R}^{2}=0.906$.

$\mathrm{F}=19.375, \mathrm{p}=0.048$ - this shows the high adequacy of the model.

The model allows predicting future costs for the next three years (2014-2016), provided all tendencies regarding resources allocated for medical devices, diet foods for special medicinal purposes and medicinal products remain constant, following the regression model equation. The values for the NHIF budget for ambulatory conditions are shown on Table 1.

The second model describes the relationship between only medicines' expenses, which are set aside by the NHIF. In the regression model, the reimbursed sum, delegated only to medicines, also follows a linear curve (Figure 2). Linear regression model, built from already existing data by the NHIF, which show the reimbursed sums for medicinal products for the base year $1=2010$, and subsequent years $2=2011,3=2012,4=2013$ is on Figure 2. 


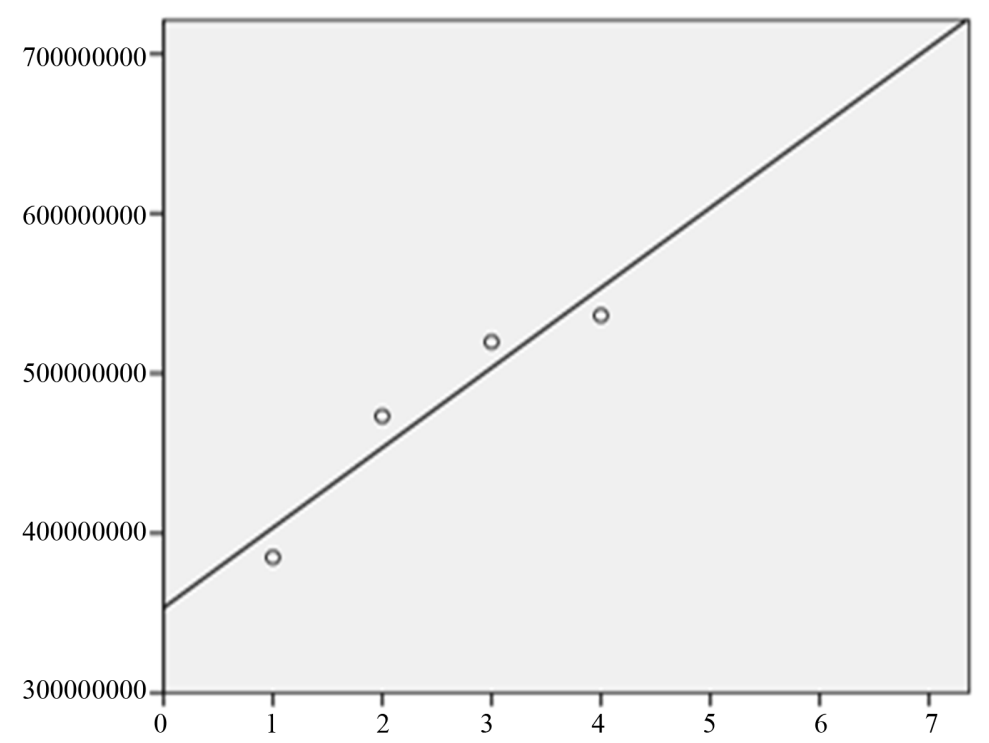

O Observed

Figure 1. Model for the ambulatory therapy, medical devices and dietary foods expenses.

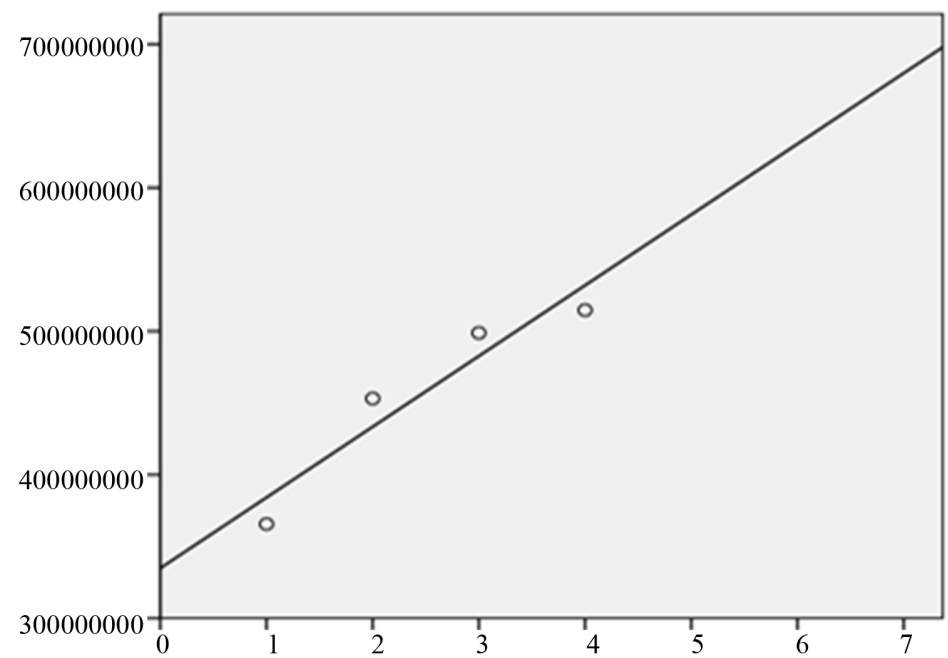

- Observed

Figure 2. Model for the medicines' expenses.

Table 1. Forecast for the sum reimbursed by the NHIF for a period of three years.

\begin{tabular}{cccc}
\hline $\mathbf{N}$ & Year & $\begin{array}{c}\text { Expenditures for ambulatory medicines therapy, } \\
\text { medical devices and dietary food (BGN) }\end{array}$ & $\begin{array}{c}\text { Expected expenditures after } \\
\text { modeling (BGN) }\end{array}$ \\
\hline 1 & 2010 & $384,837,144.00$ & $403,360,000.00$ \\
2 & 2011 & $473,159,954.00$ & $453,420,000.00$ \\
3 & 2012 & $519,609,009.10$ & $503,480,000.00$ \\
4 & 2013 & $536,209,002.00$ & $553,540,000.00$ \\
5 & 2014 & & $603,600,000.00$ \\
6 & 2015 & & $653,660,000.00$ \\
7 & 2016 & & $703,720,000.00$ \\
\hline
\end{tabular}


Regression equation that describes the model is:

Reimbursed sum $=334,800,000+98,280,000 \times$ year.

Correlation coefficient $\mathrm{R}=0.951$.

Coefficient of determination $\mathrm{R}^{2}=0.904$.

$\mathrm{F}=18.84, \mathrm{p}=0.049$ - this shows the high adequacy of the model.

If all current tendencies regarding allocation of resources for medical products remain constant, the value of the sums reimbursed by the NHIF is expected to reach the level of 680 millions of BGN shown in Table 2.

Apart from expenditures over medicines, medical devices and diet foods, there is also a change in the number of reimbursed medicines. The changes in the number of reimbursed medicines are extremely dynamic and influence the cost. This was the reason we developed a third model, which analyzes the effect the change in number of reimbursed medical products has (Figure 3 and Table 3).

The statistical method was also based on a linear regression model, built from existing data for the number of reimbursed products by the NHIF, with a base year $1=2010$, and subsequent years $2=2011,3=2012,4=$ 2013.

The regression equation used was:

Reimbursed sum $=1153.5+165.9 \times$ year.

Correlation coefficient $\mathrm{R}=0.959$.

Coefficient of determination $\mathrm{R}^{2}=0.92$.

$\mathrm{F}=22.938, \mathrm{p}=0.041$-which shows the high adequacy of the model.

It all the tendencies remain unchanged the expected number of reimbursed medicines in 2016 is 2315 (Table 3).

The reimbursed sum for medicines for rare diseases is also constantly increasing and follows a linear regression curve too (Figure 4). The mathematical model is based on a linear regression model, built from existing date regarding the reimbursed sums by the NHIF for rare disease, with a base year $1=2011$ and subsequent $2=$ 2012, $3=2013$, all shown on the $\mathrm{x}$-axis. The regression equation, which describes the model, is as follows:

Table 2. Expected reimbursed sum for medicines expenses.

\begin{tabular}{cccc}
\hline $\begin{array}{c}\text { Year sequence } \\
\text { number }\end{array}$ & Year & $\begin{array}{c}\text { Reimbursed sum for } \\
\text { medical products (BGN) }\end{array}$ & $\begin{array}{c}\text { Expected } \\
\text { sum (BGN) }\end{array}$ \\
\hline 1 & 2010 г. & $365,626,001.00$ & $384,080,000.00$ \\
2 & 2011 г. & $453,076,527.00$ & $433,360,000.00$ \\
3 & 2012 г. & $498,805,448.00$ & $482,640,000.00$ \\
4 & 2013 г. & $514,647,334.00$ & $531,920,000.00$ \\
5 & 2014 г. & & $581,200,000.00$ \\
6 & 2015 г. & & $630,480,000.00$ \\
7 & $2016 г$. & & $679,760,000.00$ \\
\hline
\end{tabular}

Table 3. Prognosis for the number of reimbursed medicines.

\begin{tabular}{cccc}
\hline $\begin{array}{c}\text { Year sequence } \\
\text { number }\end{array}$ & Year & $\begin{array}{c}\text { Number of medical products } \\
\text { reimbursed by the NHIF (n) }\end{array}$ & $\begin{array}{c}\text { Expected } \\
\text { number (n) }\end{array}$ \\
\hline 1 & $2010 г$. & 1264 & 1319 \\
2 & 2011 г. & 1542 & 1485 \\
3 & 2012 г. & 1704 & 1651 \\
4 & $2013 г$. & 1763 & 1817 \\
5 & 2014 г. & & 1983 \\
6 & $2015 г$. & & 2149 \\
7 & $2016 г$. & & 2315 \\
\hline
\end{tabular}




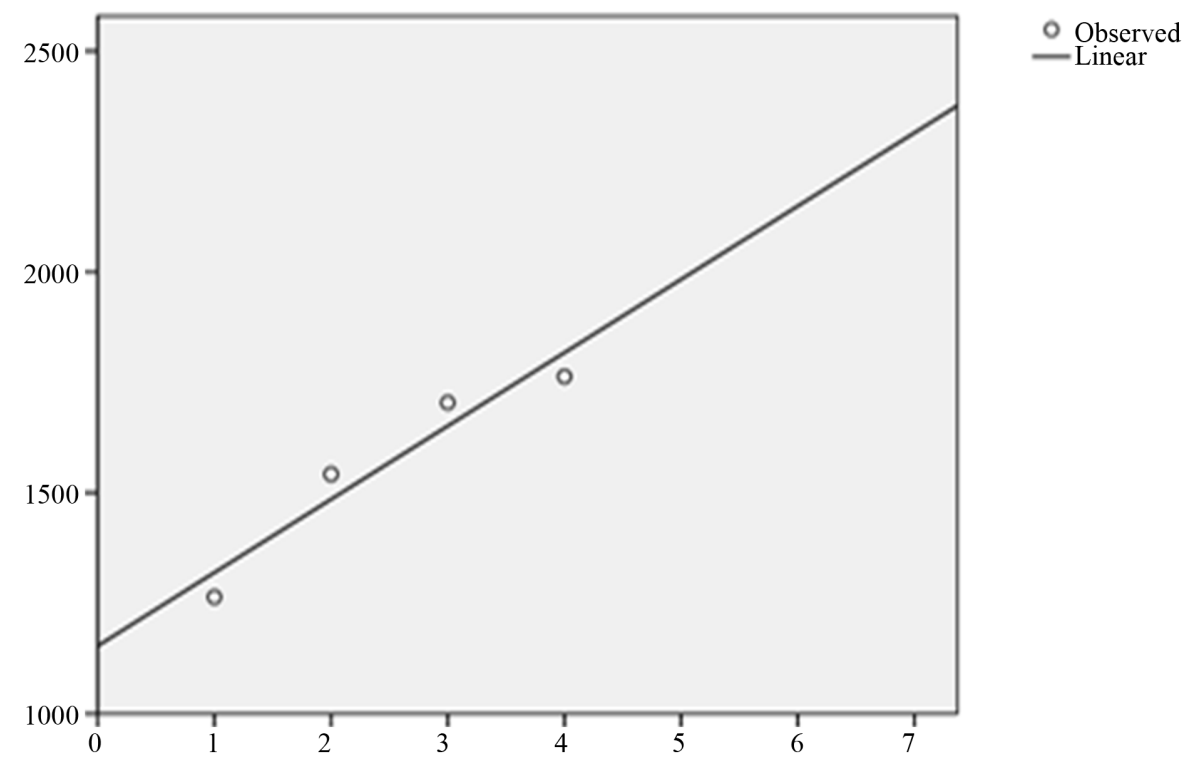

Figure 3. Model of the change in number of reimbursed medicines.

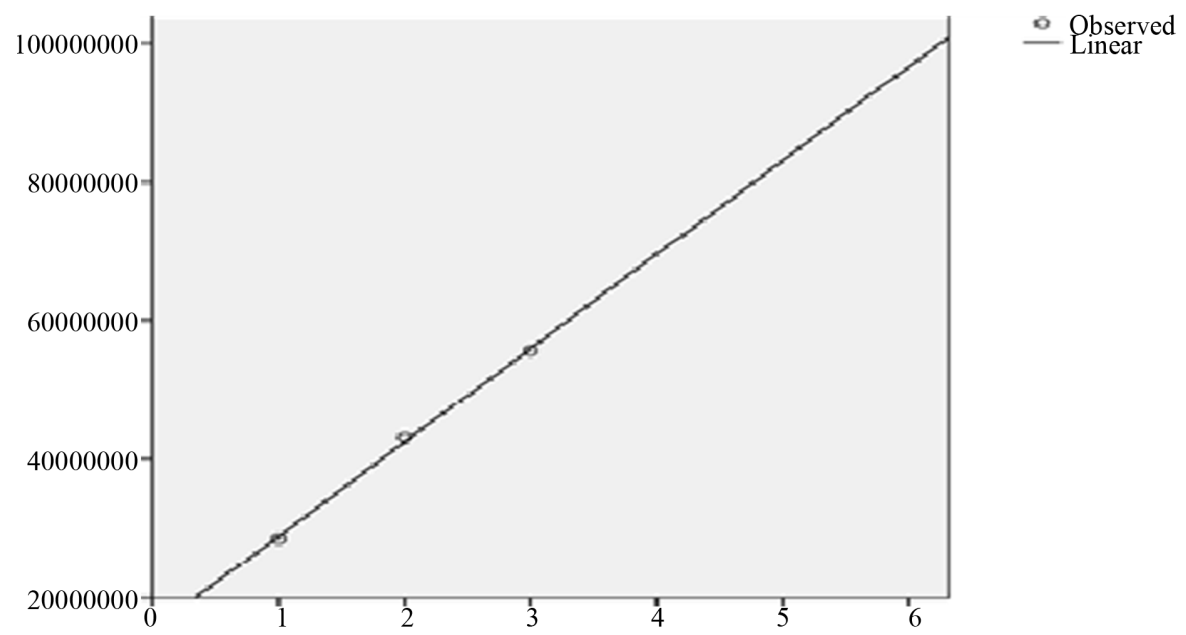

Figure 4. Model of the change in expenses for medicines for rare diseases.

Reimbursed sum $=15,430,000+13,520,000 \times$ year.

Correlation coefficient $\mathrm{R}=0.999$.

Coefficient of determination $\mathrm{R}^{2}=0.998$.

$\mathrm{F}=613.099, \mathrm{p}=0.026$ - this coefficient shows the extremely high adequacy of the model. If the current tendencies in financing the pharmacotherapy of rare diseases continue, the expected value for the sums reimbursed by the NHIF will be in the vicinity of 96.5 million BGN for the next three years (Table 4).

\section{Discussion}

In Bulgaria, the financing of pharmacotherapy for rare diseases follows the well-established principles regarding the financing of all other medicines, which increases the risk of under financing both treatments for patients suffering from rare diseases, as well as treatments for regular citizens. This is because both groups of patients rely on funds allocated by the NHIF [15].

The data from the budget of reimbursed sums for treatment of rare diseases show that the pharmacotherapy of these illnesses requires significant financial resources, which necessitates the careful allocation of funds for the 
Table 4. Prognosis for the reimbursed sum for pharmacotherapy of rare diseases.

\begin{tabular}{cccc|}
\hline Year sequence number & Year & Reimbursed sum (BGN) & Expected sum (BGN) \\
\hline 1-base & 2011 г. & $28,629,092.20$ & $28,950,000.00$ \\
2 & 2012 г. & $43,092,953.98$ & $42,470,000.00$ \\
3 & $2013 г$. & $55,665,580.58$ & $55,990,000.00$ \\
4 & $2014 \Gamma$. & & $69,510,000.00$ \\
5 & $2015 г$. & & $83,030,000.00$ \\
& 2016 r. & & $96,550,000.00$ \\
\hline
\end{tabular}

anticipated costs [10] [16]. This will ensure patients' access to modern therapy, without it putting a strain on the limited community resources [17].

The existing differences in the average cost of rare diseases' treatment between different regions, could be based not only financial, but medical factors as well. An added curiosity is the fact that, in many small cities, the pharmacotherapy cost is higher than that in cities, which have medical universities [3] [6].

This deviates from results in other similar studies, which show that cities with universities have a wider variety of prescribed medicines and the pharmacotherapy costs are higher [4] [6]. The interpretation for our result could be that the lack of qualified healthcare professionals and knowledge regarding the treatment of such a rare disease, lead to inadequate prescriptions and treatments, which causes a significant increase in the average cost of pharmacotherapy. There needs to be a revision of the medical basis for the differences shown in this study. These differences are statistically significant and relate to the discrepancies in costs for therapy of rare diseases in different regions. Despite the fact that the number of patients with rare diseases is limited, they still require significant financial resources. This in turn necessitates the need to thoroughly analyze the reasons behind any and all deviations in pharmacotherapy costs, from a medical and therapeutic point of view, because, in some cases, the high expenditures do not necessarily mean high therapeutic effectiveness in these groups of patients.

Our regression line follows a straight linear curve, which is increasing. This is in contrast to other models analyzing the pharmacotherapy costs for rare diseases [5]. The possible reason for this could be in the short timespan which our data follows, which does not allow for more long-term prognoses to be made.

An emphasis should be placed on the fact that, in comparison with other European countries, the expenditures on the pharmacotherapy of rare diseases in Bulgaria are not sufficient, which indicates that the tendency in their constant increase will be longer compared to that in other member countries [2].

\section{Conclusions}

In the background of a dynamic regulatory environment and intensive research activity in the field of rare diseases and orphan drugs, the limited and constantly restrictive access of Bulgarian patients is extremely worrying.

The number of patients, as well as the budget allocated for orphan drugs is increasing in time, with the addition of the critical fact that the oncology drugs were transferred to the NHIF. This is a positive result based on a number of factors, but also reveals the importance of carefully predicting and allocating the funds needed for orphan drugs. The model analyzing costs for pharmacotherapy shows that these expenses will increase linearly in the next three years, which in turn will put the financial capabilities of the NHIF to the test, as well as limit the access of patients to orphan drugs.

\section{References}

[1] Ministry of Health (2012) National Program for Rare Diseases. www.rare-bg.com/wp-content/uploads/2013/01/NPRD 2009-20131.doc

[2] EC (2007) Rare Diseases Challenge for the Society. www.ec.europa.eu/health/archive/ph_threats/non_com/docs/raredis_comm_bg.pdf

[3] Zlatareva, A., Tachkov, K., Stoicheva, M., Georgieva, S., Momekov, G. and Petrova, G. (2014) Financial Analysis of the Access to Pharmacotherapy for Rare Diseases in Bulgaria. Modern Economy, Submitted for Publication.

[4] Georgieva, S., Petrova, G., Dimitrova, M., Peikova, L., Paskalev, E., Filipov, J. and Zlatkov, B. (2013) Prospective 
Study of the Changes in Pharmacotherapy Cost of Adult Kidney Transplant Patients in Bulgaria. Modern Economy, 4, 827-831. http://dx.doi.org/10.4236/me.2013.412089

[5] Schey, C., Milanova, T. and Hutchings, A. (2011) Estimating the Budget Impact of Orphan Medicines in Europe: 2010-2020. Orphanet Journal of Rare Diseases, 27, 62. http://dx.doi.org/10.1186/1750-1172-6-62

[6] Savova, A., Kamusheva, M., Georgieva, S., Stoimenova, A. and Petrova, G. (2013) Budget Impact Analysis of Chronic Myeloid Leukemia Treatment in Bulgaria. Biotechnology and Biotechnology Equipment, 27, 3595-3598. http://dx.doi.org/10.5504/BBEQ.2012.0075

[7] Field, M. and Boat, T. (2010) Rare Diseases and Orphan Products: Accelerating Research and Development. National Academies Press, Washington DC.

[8] Kamusheva, M., Stoimenova, A., Doneva, M., Zlatareva, A. and Petrova, G. (2013) A Cross Country Comparison of Reimbursed Orphan Medicines in Bulgaria, Greece, Macedonia. Biotechnology and Biotechnology Equipment, 27, 4186-4193. http://dx.doi.org/10.5504/BBEQ.2013.0066

[9] Zlatareva, A., Lakic, D., Kamusheva, M., Spaskov, D., Momekov, G. and Petrova, G. (2013) Analysis of Access to Orphan Drugs in Five Neighboring European Countries-Bulgaria, Greece, Macedonia, Romania and Serbia. World Journal of Pharmacy and Pharmaceutical Sciences, 2, 2278-4357.

[10] O’Sullivan, A. (2012) Should Orphan Drugs Be Subjected to Value-Based Assessments. 17th Annual Meeting of International Society of Pharmacoeconomics \& Outcomes Research, 4 June 2012. http://www.ispor.org/meetings/WashingtonDC0512/releasedpresentations/IP5-Sullivan.pdf

[11] Simoens, S. (2011) Pricing and Reimbursement of Orphan Drugs: The Need for More Transparency. Orphanet Journal of Rare Diseases, 6, 42. http://dx.doi.org/10.1186/1750-1172-6-42

[12] Inotai, A., Petrova, G., Vitezic, D. and Kaló, Z. (2014) Benefits of Investment into Modern Medicines in CentralEastern European Countries. Experts Review of Pharmacoeconomics and Outcomes Research, 14, 71-79. http://dx.doi.org/10.1586/14737167.2014.868314

[13] Kanavos, P., et al. (2011) Differences in Costs of and Access to Pharmaceutical Products in the EU. DirectorateGeneral for Internal Policies, European Parliament. http://www.lse.ac.uk/businessAndconsultancy/LSEConsulting/pdf/pharmaceuticals.pdf

[14] Bignami, F. (2007) Eurordis Survey on Orphan Drugs Availability in Europe. Presented at the 6th Eurordis Round Table of Companies Workshop, Barcelona. http://www.eurordis.org/IMG/pdf/2007ODsurvey-eurordis.pdf

[15] MH (2009) National Council for Rare Diseases. http://www.mh.government.bg/Articles.aspx?lang=bg-BG\&pageid=476

[16] Carone, G., Schwierz, C. and Xavier, A. (2012) Cost-Containment Policies in Public Pharmaceutical Spending in the EU. European Commission, Directorate General for Economic and Financial Affairs. www.ec.europa.eu/economy_finance/publications/economic_paper/2012/pdf/ecp_461_en.pdf

[17] Massol, J., Puech, A. and Boissel, J.-P. (2007) How to Anticipate the Assessment of the Public Health Benefit of New Medicines? Thérapie, 62, 427-435. http://dx.doi.org/10.2515/therapie:2007071 